\title{
KONSEP HIDUP DALAM LEKSIKON MASYARAKAT ADAT KASEPUHAN BANTEN KIDUL KECAMATAN CISOLOK KABUPATEN SUKABUMI (KAJIAN ETNOLINGUISTIK)
}

\section{LIFE CONCEPT IN THE LEXICON OF INDIGENOUS COMMUNITY OF KASEPUHAN BANTEN KIDUL CISOLOK DISTRICT SUKABUMI (ETNOLINGUISTIC STUDY)}

\author{
Dodik Murdiyanto Laksmana Putra, Wakit Abdullah Rais, Sawardi \\ Pascasarjana S2 Linguistik Deskriptif, Universitas Sebelas Maret, \\ Jalan Ir. Sutami 36, Kentingan, Surakarta \\ Po-sel: dodikmoerdijanto@student.uns.ac.id, abdullahwakit@yahoo.com, \\ fxsawardi@staf.uns.ac.id
}

*) Naskah diterima: 13 November 2019; direvisi: 15 November 2019; disetujui: 3 Desember 2019

\begin{abstract}
Abstrak
Penelitian ini bertujuan untuk mendeskripsikan klasifikasi kultural dan konsep hidup yang tercermin dari leksikon bahasa Sunda di masyarakat adat kasepuhan Banten Kidul. Tempat penelitian untuk mengambil objek kajian ini, yakni tiga Kampung Adat Kasepuhan yang mempunyai keistimewaan masih memegang teguh adat istiadat leluhurnya sejak lebih dari 650 tahun yang lalu, yaitu Kasepuhan Ciptagelar, Sinarresmi, dan Ciptamulya yang terletak di Kecamatan Cisolok, Kabupaten Sukabumi. Fokus penelitian ini terletak pada leksikonleksikon politik (sistem kepengurusan adat), sistem kepercayaan, dan ritual (upacara menghargai leluhur) bahasa Sunda di Kasepuhan Ciptagelar, Sinarresmi, dan Ciptamulya dengan menggunakan kajian etnolinguistik. Penelitian ini menggunakan metode observasi partisipatif sehingga pemeriksaan dokumentasi dan observasi secara langsung ditemukan peneliti lewat partisipasi aktif. Teknik pengumpulan data yang digunakan adalah observasi, wawancara, dan dokumentasi. Teknik analisis data dalam penelitian ini melibatkan tiga komponen, yaitu sajian data, reduksi data, dan penarikan kesimpulan. Klasifikasi leksikon bahasa Sunda yang ditemukan di Kasepuhan Ciptagelar, Sinarresmi, dan Ciptamulya berupa kata dan frasa yang berkategori nominal dan verbal. Klasifikasi leksikon bahasa Sunda yang ditemukan di Kasepuhan Ciptagelar, Kasepuhan Ciptamulya, dan Kasepuhan Sinarresmi Kecamatan Cisolok, Kabupaten Sukabumi berupa kata dan frasa (nominal dan verbal) yang dikategorikan dalam tiga kategori yaitu politik (sistem kepengurusan adat), sistem kepercayaan, ritual (upacara menghargai leluhur). Leksikon-leksikon yang ditemukan dalam kategori politik (sistem kepengurusan adat) terdapat 14 leksikon, yaitu sesepuh girang, baris kolot, gandek, ema beurang, tukang bebersih (kemit), penghulu, bengkong, paraji, tukang moro, dukun, ngurus leuit, canoli, tukang dapur, dan tukang panday. Selanjutnya, leksikon-leksikon bahasa Sunda yang ditemukan dalam kategori sistem kepercayaan terdapat 15 leksikon, yaitu mupusti pare lain migusti, saiketan sabeungkutan, ngajaga leuweng, incu putu, leuweung kolot, leuweung titipan, leuweung sempalan, upacara (ngaseuk, mipit, nganyaran), tatali paranti karuhun, tetekon, tilu sapamilu, dua sakarupa, hiji eta keneh, nyanghulu ka hukum, nunjang ka nagara, mufakat jeung balea, ucap lampah kalawan tekad, wedal, dan leuit. Terakhir adalah temuan leksikon bahasa Sunda yang dikategorikan ritual (upacara menghargai leluhur) data ditemukan sebanyak 13, antara lain ngaseuk, sapangjadian pare, sawenan, beberes mager, ngarawunan, mipit, nutu, ronggokan, nganyaran, tutup nyambut, turun nyambut, seren taun, dan beberes bengkong.
\end{abstract}

Kata Kunci: kasepuhan, etnolinguistik, leksikon, bahasa Sunda 


\begin{abstract}
This study aims to describe the cultural classification and life concepts that are reflected in the lexicon of Sundanese language in the indigenous people of Kasepuhan Banten Kidul. The location of the research to take the object are 3 Kasepuhan Customary Villages which have the privilege of still holding on to the customs of their ancestors since more than 650 years ago, namely Kasepuhan Ciptagelar, Sinarresmi, and Ciptamulya in Cisolok District, Sukabumi. The focus of this research lies in political lexicons (customary management systems), belief systems, and rituals (ceremonies honoring ancestors) in Sundanese language in those three Kasepuhan using ethnolinguistic studies. This study uses a participatory observation method so that the examination of documentation and observation is directly found by the researcher through active participation. Data collection techniques used were observation, interviews, and documentation. Data analysis techniques in this study involved three components, namely data presentation, data reduction, and drawing conclusions. Sundanese lexicon classification found in Kasepuhan Ciptagelar, Sinarresmi, and Ciptamulya is in the form of words and phrases that are categorized nominal and verbal. Sundanese lexicon classifications found in Kasepuhan Ciptagelar, Kasepuhan Ciptamulya, and Kasepuhan Sinarresmi Cisolok District, Sukabumi Regency is in the form of words and phrases (nominal and verbal) are categorized in three categories, namely politics (traditional management system), trust systems, and rituals (ceremonies honoring ancestors). The lexicons found in the category of politics (traditional management system) are 14 lexicons, namely sesepuh girang, baris kolot, gandek, ema beurang, tukang bebersih (kemit), penghulu, bengkong, paraji, tukang moro, dukun, ngurus leuit, canoli, tukang dapur, and tukang panday. Furthermore, Sundanese lexicons found in the belief system category contained 15 lexicons, namely mupusti pare lain migusti, saiketan sabeungkutan, ngajaga leuweng, incu putu, leuweung kolot, leuweung titipan, leuweung sempalan, upacara (ngaseuk, mipit, nganyaran), tatali paranti karuhun, tetekon, tilu sapamilu, dua sakarupa, hiji eta keneh, nyanghulu ka hukum, nunjang ka nagara, mufakat jeung balea, ucap lampah kalawan tekad, wedal, leuit. Finally, the findings of the Sundanese lexicon categorized as Rituals (ceremonies honoring ancestors) as many as 13 data found namely ngaseuk, sapangjadian pare, sawenan, beberes mager, ngarawunan, mipit, nutu, ronggokan, nganyaran, tutup nyambut, turun nyambut, seren taun, and beberes bengkong.
\end{abstract}

Keywords: kasepuhan, ethnolinguistics, lexicon, sundanese

\section{PENDAHULUAN}

Berdasarkan cerita turun temurun dari para leluhur, masyarakat adat Kasepuhan Ciptagelar, Ciptamulya dan Sinarresmi berasal dari Kerajaan Pajajaran-Bogor. Catatan sejarah menunjukkan bahwa pada pertengahan abad XVI Masehi, Pajajaran ditaklukan oleh Kesultanan Islam Banten. Penaklukan dan penghancuran kerajaan Sunda-Hindu terakhir di Jawa ini dipimpin oleh Sultan Maulana Yusuf dari Banten. Sebelum pusat Kerajaan diserang, Raja Prabu Suryakancana, yang dikenal dengan nama Prabu Pucuk Umun, raja terakhir Pakuan Pajajaran telah menugaskan kepada para Demang untuk menyelamatkan barangbarang pusaka agar tidak jatuh ke tangan musuh.
Ibu Kota Kerajaan Pajajaran oleh masyarakat Kasepuhan diyakini berada di seputar Batu Tulis, Bogor sekarang. Raja beserta para pengiringnya pergi ke Palasari - Pandeglang, Banten. Sedangkan para Demang menuju ke daerah Jasinga Bogor untuk selanjutnya pindah ke Kampung Lebak Binong Kabupaten Lebak, Banten. Selanjutnya mereka bergerak ke Kampung Cipatat, Kabupaten Bogor, Jawa Barat, kemudian pindah lagi ke Kampung Lebak Larang, Kabupaten Lebak, Banten. Dari sini mereka pindah lagi ke Kampung Lebak Binong, terus ke Kampung Tegal Lumbu, Kabupaten Lebak, Banten. Pengungsian ini kemudian berlanjut ke Kampung Cicadas, Kabupaten Sukabumi, Jawa Barat dan selanjutnya pindah lagi ke Kampung Bojong Cisono, Kabupaten Lebak, Banten, sebelum 
akhirnya pindah lagi ke Kampung Cicemet, Kabupaten Sukabumi, Jawa Barat. Menurut cerita turun temurun itu pula, perpindahan yang begitu sering dan mencakup wilayah yang luas ini adalah sebagai upaya untuk menghapus jejak mereka dari kejaran pihak Kesultanan Banten.

Hal lain adalah mereka tetap tidak mau tunduk di bawah struktur kekuasaan Banten. Pada tahun 1957 pusat Kasepuhan, pindah lagi ke Kampung Cikaret (Sirnaresmi), untuk kemudian ke Kampung Ciganas (Sirna Rasa) pada tahun 1972 sebelum ke Kampung Lebak Gadog (Linggar Jati) tahun 1982. Pada tahun 1983 mereka pindah lagi ke Kampung Datar Putat (Cipta Rasa) dan terakhir pada 2000 ke Kampung Cikarancang (Ciptagelar) sampai sekarang. Semua tempat perpindahan ini termasuk daerah Kabupaten Sukabumi- Jawa Barat. Perpindahan yang terjadi kemudian ini, menurut para pemuka adat Kasepuhan adalah sebuah upaya untuk menapak-tilasi dan mengurus wilayah adat Kasepuhan, yang terletak dalam tiga kabupaten, yaitu Bogor, Sukabumi dan Lebak dan berada di seputar kawasan Taman Nasional Gunung Halimun. Menurut cerita turun temurun, suatu saat kelak masyarakat adat Kasepuhan Ciptagelar, Ciptamulya, dan Sinarresmi bersama-sama dengan Kasepuhan Citorek dan Cicarucub, ketiganya memiliki hubungan kekerabatan, akan kembali lagi ke Pusat Kerajaan Pajajaran di Batu Tulis Bogor (Sumber, Buku Adat Komunitas Masyarakat Adat Kasepuhan).

Agar penelitian ini tepat sasaran dan fokus, maka penelitian ini berlandaskan ilmu etnolinguistik yang mengkaji kaitan antara fakta bahasa dan fakta budaya. Menurut Palmer yang mendeskripsikannya melalui istilah linguistik budaya, berarti sebuah disiplin ilmu yang muncul sebagai perpaduan dari ilmu bahasa dan budaya (Palmer, 1996, hlm. 36). Linguistik budaya secara mendasar tidak hanya berhubungan dengan kenyataan objektif, tetapi juga mengenai bagaimana orang atau masyarakat itu berbicara, mengenai dunia yang mereka gambarkan sendiri. Linguistik budaya berhubungan dengan makna atau arti yang bersifat interpretatif (penafsiran), atas keseluruhan konteks (linguistik, sosial, dan budaya).

Senada dengan linguistik kebudayaan adalah sebuah studi yang meneliti hubungan intrinsik antara bahasa dan budaya, bahasa dipandang sebagai fenomena budaya yang kajiannya berupa language in cultural atau language and cultural (Riana, 2003, hlm. 8). Etnolinguistik adalah suatu ilmu bagian yang pada asal mulanya erat bersangkutan dengan ilmu antropologi. Objek kajian penelitiannya berupa daftar kata-kata, pelukisan dari ciri-ciri, dan pelukisan dari tata bahasa dan bahasa-bahasa lokal (Koentjaraningrat, 1981, hlm. 2). Hingga kaitan antara keduanya akan saling beriringan seiring bertambahnya waktu, makna kebudayaan tidak akan bisa terlepas dari bahasa yang digunakan. Karena melalui bahasa dapat diperjelas objek yang dihubungkan antara budaya dan masyarakat pelaksana, seperti dari segi bentuk, fungsi, dan makna leksikal yang ada dalam kebudayaan tersebut.

Begitu pula dengan kebudayaan yang terdapat di tengah-tengah masyarakat adat kasepuhan yang berada di Kecamatan Cisolok, Kabupaten Sukabumi, yaitu Kasepuhan Ciptagelar, Kasepuhan Ciptamulya, dan Kasepuhan Sinarresmi. Banyak leksikon-leksikon bahasa Sunda yang menggambarkan konsep hidup dalam tiga kasepuhan ini. Misalnya, leksikon bahasa Sunda dalam falsafah hidup tentang bertani, ada istilah kasepuhan mupusti pare, lain migusti yang berarti mereka sangat menghargai serta memuliakan padi tapi bukan berarti menuhankan. Kebersamaan (incu putu) Kasepuhan Ciptagelar, Kasepuhan Ciptamulya, dan Kasepuhan Sinarresmi 
inilah yang membuat mereka semakin istimewa. Banyak peraturan-peraturan adat yang masih terjaga dan ditaati sejak 650 tahun yang lalu, mengingat karena tiga kasepuhan ini merupakan kasepuhan inti dari Kesatuan Adat Kasepuhan Banten Kidul yang terletak di kaki Gunung Halimun, Desa Sinar Resmi, Kecamatan Cisolok, Kabupaten Sukabumi. Ada juga etika yang dianjurkan sebagai masyarakat adat kasepuhan diwajibkan memakai "ikat kepala" saiketan sabeungkeutan yang berarti sesama masyarakat kasepuhan harus saling terikat menjaga kebersamaan persaudaraan.

Kasepuhan Ciptagelar dipimpin oleh Abah Ugi, Kasepuhan Sinar Resmi dipimpin oleh Abah Asep Nugraha, dan Kasepuhan Ciptamulya dipimpin oleh Abah Uum Sukmawijaya. Pemimpin-pemimpin kasepuhan tersebut ditentukan dari garis keturunan leluhur dan wangsit, yang menjalankan segala sesuatunya berdasarkan restu semesta. Karena kalau mereka melanggar aturan adat, maka mereka akan kualat (Kabendon). Itulah beberapa contoh leksikonleksikon bahasa Sunda yang mampu mewakili konsep hidup Kasepuhan Ciptagelar, Kasepuhan Ciptamulya, dan Kasepuhan Sinarresmi. Agar penelitian ini tepat sasaran dan fokus, maka penelitian ini berlandaskan ilmu etnolinguistik yang mengkaji kaitan antara fakta bahasa dan fakta budaya. Sedangkan temuan-temuan leksikon bahasa Sunda yang ada di konsep hidup Kasepuhan Ciptagelar, Kasepuhan Ciptamulya, dan Kasepuhan Sinarresmi merupakan leksikon-leksikon yang mampu mewakili aktivitas, kepercayaan, falsafah hidup, dan ritual-ritual sebagai bentuk penghargaan terhadap leluhur.

Tabel 1. Contoh Temuan Leksikon

\begin{tabular}{|l|l|l|}
\hline \multicolumn{1}{|c|}{ Politik } & \multicolumn{1}{|c|}{ Kepercayaan } & \multicolumn{1}{|c|}{ Upacara Ritual } \\
\hline Gandek : Asisten tutunggul & Hutan itu ada 3, yaitu & Seren Taun: \\
atau ketua adat (Abah) & $\begin{array}{l}\text { Hutan Tua (Leuweung } \\
\text { Kolot), Hutan } \\
\text { Titipan/ Keramat } \\
\text { (Leuweung Titipan) dan }\end{array}$ & $\begin{array}{l}\text { tradisi dari } \\
\text { seluruh }\end{array}$ \\
& Hutan Sempalan/ & kegiatan \\
& bukaan (Leuweung & pertanian \\
& Sampalan) & \\
\hline
\end{tabular}

Penelitian yang relevan dalam area etnolinguistik sendiri sudah banyak dilakukan oleh beberapa peneliti. Antara lain, adalah penelitian yang dilakukan oleh Rais (2012) tentang cara memanfaatkan lingkungan alam yang tercermin dalam ekspresi verbal dan non verbal nelayan di Pesisir Selatan Kebumen. Rais (2012) meneliti mengenai kearifan lokal dalam bahasa dan budaya Jawa orang Samin di Kabupaten Blora. Selanjutnya, Tondo (2013) meneliti menggunakan kajian etnolinguistik 
tentang bahasa minoritas masyarakat Hamap dalam perkebunan jagung, kemudian ada juga Fernandez (2008) tentang kategori dan ekspresi linguistik saat menuturkan bahasa Jawa kepada petani dan nelayan. Referensi lainnya adalah Sugianto (2015) tentang kajian etnolinguistik terhadap pakaian adat Warok yang berasal dari Ponorogo.

Selanjutnya, Wua dan Marwati (2019) mendeskripsikan bentuk-bentuk leksikon penunjuk waktu dalam bahasa Muna. Penelitian tersebut menemukan leksikon penunjuk waktu dalam bahasa Muna diklasifikasikan menjadi monomorfemis, polimorfemis, kelas kata, dan frasa. Senada dengan penelitian tersebut, Maulidiah (2019) menemukan istilah-istilah yang sering digunakan dalam keseharian masyarakat melayu Asahan dalam bentuk 1) monomorfemis, 2) polimorfemis. untuk melestarikan kearifan lokal dan memaparkan istilah bahasa yang muncul dalam pelestarian bahasa yang digunakan masyarakat melayu asahan dalam kesehariannya. Temuan leksikon monomorfemis diantaranya adalah tapak, dogil, kerabu, hambus, hajab, sunge, nyonyak, menggek, bengak, ghumah, gallon, gilo, bosar, mogah, odan, budak, mentel, ondak, togap, muko, cemano, kambur, cak, kedekut, pelosu, okap, pokak, perigi. Temuan leksikon polimorfemis seperti leksikon, tasodak, tagolak, melalak, pambongkak, pimomat, menggelatuk, mencagil, bekombur, melunjak, beseloro, berondok, bosenandong, betujah, betandang.

Selepas itu, Nurnaningsih (2019) mendeskripsikan tentang Kearifan lokal di balik bahasa Jawa dalam tradisi tingkeban di Kelurahan Laweyan Kecamatan Laweyan Surakarta menarik dikaji secara Etnolinguistik. Dalam tradisi tingkeban ini terdapat kearifan lokal di balik bahasa Jawa. Ada pitutur luhur yang mendasari masyarakat melaksanakan tingkeban. Setiap benda yang disediakan untuk sesaji atau sedekah dapat diartikan nilai yang terkandung di dalamnya serta dapat pula dirangkaikan melalui nama dari benda sesaji tersebut. Misalnya: tebu yang artinya antebing kalbu. Penggunaan empat macam bunya mawar : menapa ingkang binawar, Melathi: saking kedaling lathi, Kanthil: sageda tansah kumanthil ing telenging nala. Jika diartikan ke dalam bahasa Indonesia, apa saja yang dinasehatkan oleh orang tua atau para tetua dan cerdik pandai semoga selalu dapat disimpan di lubuk hati.

Dari penelitian yang relevan sebelumnya tentang kajian etnolinguistik, dapat dideskripsikan bahwa penelitian tentang kebudayaan, pengetahuan masyarakat, dan kearifan lokal yang terdapat di dalamnya. Namun, penelitian-penelitian tersebut belum ada yang mengkaji leksikon tentang konsep hidup, kepercayaan dan upacara adat dengan kajian etnolinguistik. Oleh karena itu, penelitian ini hadir untuk menjawab bagaimana leksikon bahasa Sunda yang mampu mewakili konsep hidup Kasepuhan Ciptagelar, Kasepuhan Ciptamulya, dan Kasepuhan Sinarresmi. Dalam penelitian ini diungkap sejumlah fakta bahasa dan fakta budaya yang menyertai penggunaan leksikon yang mampu mewakili konsep hidup Kasepuhan Ciptagelar, Kasepuhan Ciptamulya, dan Kasepuhan Sinarresmi. Adapun tujuan dalam penelitian ini adalah mendeskripsikan klasifikasi kultural, serta konsep hidup yang tercermin dari leksikon bahasa Sunda di Kasepuhan Ciptagelar, Kasepuhan Ciptamulya, dan Kasepuhan Sinarresmi.

\section{METODE}

Sesuai dengan kondisi budaya bahasa yang merupakan cabang ilmu humaniora yang bersifat unik, penelitian ini menggunakan metode observasi partisipatif. Pemeriksaan, dokumentasi, dan observasi secara langsung ditemukan peneliti lewat partisipasi aktif di titik lokasi penelitian yaitu di Kasepuhan Ciptagelar, Kasepuhan Cipta- 
mulya, dan Kasepuhan Sinarresmi Kecamatan Cisolok, Kabupaten Sukabumi menggunakan pendekatan etnolinguistik. Teknik pengumpulan data yang digunakan adalah observasi, wawancara, dan dokumentasi, informan yang tepat untuk penelitian ini adalah pemimpin kasepuhan (abah). Teknik analisis data dalam penelitian ini melibatkan tiga komponen, yaitu sajian data, reduksi data, dan penarikan kesimpulan. Penelitian ini menggunakan beberapa instrumen, seperti catatan lapangan, lembar observasi, alat rekam, kartu data, dan tabel klasifikasi. Lembar observasi adalah lembaran yang nantinya akan berisi catatan leksikon bahasa Sunda selama melakukan observasi. Sementara itu, tabel klasifikasi digunakan untuk mempermudah analisis setiap leksikon juga memisahkan makna leksikon dan makna kulturalnya.

Validitas data penelitian kualitatif ini dengan teknik triangulasi (tringulation). Ada empat macam teknik triangulasi yang digunakan untuk pengecekan validitas data di dalam penelitian kualitatif meliputi (1) triangulasi data /triangulasi sumber; (2) triangulasi metode (3) triangulasi teori, (4) triangulasi peneliti (Lincon \& Guba 1985; Patton, 1980 dalam Riyadi Santosa, 2012:46) Triangulasi data yaitu teknik menyediakan data yang bervariasi, sumber data dapat diperoleh melalui kejadian, partisipan, dukumen, situs, artefak dan benda yang berkaitan dengan kejadian. Sedangkan triangulasi metode berkaitan dengan teknik memperoleh dan mengumpulkan data dari teknik observasi, simak dan catat kemudian data dari narasumber dapat diperoleh menggunakan wawancara mendalam atau dengan FGD (Focus Group Discussion). Selanjutnya triangulasi teori ialah teknik validitas data penelitian dengan teori yang berbeda. kemudian yang terakhir adalah triangulasi peneliti biasanya dilakukan untuk penelitian besar atau penelitian payung.

\section{PEMBAHASAN}

Kasepuhan berasal dari kata sepuh (bahasa Sunda) berarti tua (bahasa Indonesia) diimbuhi prefiks $k a$-dan infiks -an. Melalui dasar inilah muncul istilah kasepuhan yang merupakan tempat tinggalnya para sesepuh. Istilah sesepuh ini selain menunjukkan faktor umur (tua) tetapi juga merujuk pada model politik "sistem kepemimpinan" dari suatu kelompok adat berdasarkan pemikiran orang tua, jadi makna kasepuhan secara utuh berarti "adat kebiasaan orang tua atau nenek moyang". Kasepuhan Ciptagelar, Kasepuhan Ciptamulya, dan Kasepuhan Sinarresmi Kecamatan Cisolok, Kabupaten Sukabumi adalah kelompok yang terdaftar sebagai anggota Kasepuhan Banten Kidul yang tinggal dan menggantungkan hidupnya di sekitar Gunung Halimun.

Karakter budaya yang kuat dari kasepuhan ini tercermin dari istilah bahasa Sunda yang disebut "anu nyepeng tetekon adat tradisi" yang berarti harus tetap berpegang teguh dan wajib melestarikan budaya leluhur. Hal ini sejalan dengan kaitannya antara fakta bahasa dan fakta budaya yang berlaku di Kasepuhan Ciptagelar, Kasepuhan Ciptamulya, dan Kasepuhan Sinarresmi. Selain itu memang bahasa adalah hasil puncak suatu budaya. Karena peran bahasa itu sendiri yang bersifat persuasif, sehingga mampu mengarahkan pikiran melalui kemampuan berbahasa dan kemampuan retorika. Berdasarkan hal tersebut, artinya bahasa dalam hal ini disebut leksikon yang dipergunakan atau diucapkan oleh suatu kelompok masyarakat sebagai refleksi atau cermin keseluruhan budaya masyarakat tersebut. Adapun hasil analisis temuan konsep hidup yang tercermin dari leksikon bahasa Sunda di Kasepuhan Ciptagelar, Kasepuhan Ciptamulya, dan Kasepuhan Sinarresmi terklasifikasi sebagai berikut. 
A. Politik (Sistem Kepengurusan Adat)

Dalam kesehariannya Kasepuhan Ciptagelar, Kasepuhan Ciptamulya, dan Kasepuhan Sinarresmi diatur dan dipimpin oleh kepala adat yang biasa dipanggil Abah. Melalui Tabel 2 akan dideskripsikan leksikon- leksikon khas bahasa Sunda yang masuk dalam struktur organisasi kasepuhan sebagai pembantu kepala adat melaksanakan tugas-tugas dalam memimpin kasepuhan itu sendiri.

Tabel 2. Leksikon dalam Politik (Sistem Kepengurusan Adat) di Kasepuhan Ciptagelar, Kasepuhan Ciptamulya, dan Kasepuhan Sinarresmi.

\begin{tabular}{|c|l|l|}
\hline No & \multicolumn{1}{|c|}{ Leksikon } & \multicolumn{1}{c|}{ Deskripsi } \\
\hline 1 & Sesepuh girang & Pemimpin komunitas kasepuhan \\
\hline 2 & Baris kolot & $\begin{array}{l}\text { Pembimbing, penasihat yang memberikan } \\
\text { pertimbangan kepada Sesepuh girang }\end{array}$ \\
\hline 3 & Gandek & Asisten tutunggul/ketua adat (Abah) \\
\hline 4 & Ema beurang & Juru rias (upacara adat) \\
\hline 5 & Kemit & Keamanan (ronda) \\
\hline 6 & Penghulu & Pemimpin ritual keagamaan \\
\hline 7 & Bengkong & Petugas khitan \\
\hline 8 & Paraji & Pembantu bidan desa (proses melahirkan) \\
\hline 9 & Tukang moro & Pemburu di hutan \\
\hline 10 & Dukun & Dokter (mengobati masyarakat adat) \\
\hline 11 & Ngurus leuit & Pengurus lumbung padi \\
\hline 12 & Canoli & Menyimpan persediaan makanan \\
\hline 13 & Tukang dapur & Tukang masak \\
\hline 14 & Tukang panday & Pembuat senjata tajam \\
\hline
\end{tabular}

Semua perangkat adat dalam struktur kelembagaan adat bertanggung jawab kepada pimpinan tertinggi yaitu Sesepuh (yang biasa disebut "Abah"). Semua posisi dalam struktur tersebut didapat berdasarkan keturunan, bukan dipilih dan ditetapkan oleh warga Kasepuhan. Pengecualian berlaku untuk Kokolot Lembur atau sesepuh di tingkat kampung dipilih oleh incu putu atau warga Kasepuhan dalam kampung yang bersangkutan. Kokolot lembur adalah sesepuh kampung dan dalam pertemuan adat merupakan forum yang menentukan kapan akan diselenggarakannya seluruh rangkaian siklus dari persiapan lahan sampai panen. Umumnya para kokolot lembur memiliki posisi tertentu dalam struktur pengurus adat Kasepuhan.

\section{B. Sistem Kepercayaan}

Kasepuhan Ciptagelar, Kasepuhan Ciptamulya, dan Kasepuhan Sinarresmi memegang teguh kepercayaan yang digambarkan melalui istilah "anu nyepeng tetekon adat tradisi". Berarti masih melestarikan tradisitradisi warisan leluhur mereka. Pernyataan syukur dan kepercayaan yang dianut oleh Kasepuhan Ciptagelar, Kasepuhan Cipta- 
mulya, dan Kasepuhan Sinarresmi adalah sama, baik semua ritual maupun doa dalam pelaksanaannya. Ritual syukuran itu biasa disebut upacara seren taun. Berikut melalui
Tabel 3 akan dideskripsikan leksikonleksikon bahasa Sunda khas yang masuk dalam kategori sistem kepercayaan.

Tabel 3. Leksikon bahasa Sunda dalam sistem kepercayaan yang dianut Kasepuhan Ciptagelar, Kasepuhan Ciptamulya, dan Kasepuhan Sinarresmi

\begin{tabular}{|c|c|c|}
\hline No & Leksikon & Deskripsi \\
\hline 1 & Mupusti pare, lain migusti & $\begin{array}{l}\text { Memuliakan padi tapi tidak } \\
\text { menyembahnya (menuhankan) }\end{array}$ \\
\hline 2 & Saiketan sabeungkutan & $\begin{array}{l}\text { Falsafah ikat kepala yang memaknai } \\
\text { hidup antara kasepuhan harus saling } \\
\text { terikat }\end{array}$ \\
\hline 3 & Ngajaga leuweng & Aturan menjaga hutan \\
\hline 4 & Incu putu & Kebersamaan warga kasepuhan \\
\hline 5 & Leuweung kolot & Menjaga hutan tua \\
\hline 6 & Leuweung titipan & $\begin{array}{l}\text { Menjaga hutan titipan/kramat (seijin } \\
\text { sesepuh girang) }\end{array}$ \\
\hline 7 & Leuweung sempalan & Menjaga hutan bukaan \\
\hline 8 & $\begin{array}{l}\text { Upacara ngaseuk, mipit, } \\
\text { nganyaran }\end{array}$ & $\begin{array}{l}\text { Melestarikan upacara lingkungan } \\
\text { hidup (khitanan sampai pernikahan) }\end{array}$ \\
\hline 9 & Tatali paranti karuhun & Terikat oleh tradisi nenek moyangnya \\
\hline 10 & Tetekon & Aturan pemangku adat \\
\hline 11 & $\begin{array}{l}\text { Tilu sapamilu, dua sakarupa, } \\
\text { hiji eta keneh }\end{array}$ & $\begin{array}{l}\text { Tiga sejenis, dua serupa, satu itu-itu } \\
\text { juga (satu kesatuan hidup atau rasa } \\
\text { manunggal) }\end{array}$ \\
\hline 12 & $\begin{array}{l}\text { Nyanghulu ka hukum, nunjang } \\
\text { ka nagara, mufakat jeung balea }\end{array}$ & $\begin{array}{l}\text { Berpegang pada aturan, taat pada } \\
\text { negara, dan hidup bersama dalam } \\
\text { kesatuan Indonesia }\end{array}$ \\
\hline 13 & Ucap lampah kalawan tekad & $\begin{array}{l}\text { Menyelaraskan ucapan, tingkah laku } \\
\text { dan tekad }\end{array}$ \\
\hline 14 & Wedal & $\begin{array}{l}\text { Pantangan mengeluarkan padi pada } \\
\text { hari lahir }\end{array}$ \\
\hline 15 & Leuit & $\begin{array}{l}\text { Tempat menyimpan padi (simbol } \\
\text { kemakmuran) }\end{array}$ \\
\hline
\end{tabular}

Kasepuhan Ciptagelar dipimpin oleh Abah Ugi, Kasepuhan Sinarresmi dipimpin oleh Abah Asep Nugraha, dan Kasepuhan Ciptamulya dipimpin oleh Abah Uum Sukmawijaya. Pemimpin-pemimpin kasepuhan tersebut ditentukan dari garis keturunan leluhur dan wangsit, yang menjalankan segala sesuatunya berdasarkan restu se- mesta. Karena kalau mereka melanggar aturan adat, maka mereka akan kualat (Kabendon). Banyak peraturan-peraturan adat yang masih terjaga dan ditaati sejak 650 tahun yang lalu, mengingat karena tiga kasepuhan ini merupakan kasepuhan inti dari Kesatuan Adat Kasepuhan Banten Kidul yang terletak di kaki Gunung Hali- 
mun, Desa Sinarresmi, Kecamatan Cisolok, Kabupaten Sukabumi. Ada juga etika yang dianjurkan sebagai masyarakat adat kasepuhan diwajibkan memakai "ikat kepala" saiketan sabeungkeutan yang berarti sesama masyarakat kasepuhan harus saling terikat menjaga kebersamaan persaudaraan.

\section{Ritual (Upacara Menghargai Leluhur)}

Masyarakat adat Kasepuhan Ciptagelar, Kasepuhan Ciptamulya, dan Kasepuhan
Sinarresmi merupakan pemeluk agama islam yang taat, akan tetapi keimanan mereka masih disertai dan diwarnai oleh mitos dan animisme yang masih dipertahankan dengan pengawasan Abah sebagai tutunggul kasepuhan. Berikut melalui Tabel 4 akan dideskripsikan leksikon-leksikon khas bahasa Sunda yang masuk dalam upacara ritual yang dijalankan oleh Kasepuhan Ciptagelar, Kasepuhan Ciptamulya, dan Kasepuhan Sinarresmi.

\section{Tabel 4 Leksikon bahasa Sunda dalam upacara ritual yang ditemukan di Kasepuhan Ciptagelar, Kasepuhan Ciptamulya, dan Kasepuhan Sinarresmi.}

\begin{tabular}{|c|l|l|}
\hline No & \multicolumn{1}{|c|}{ Leksikon } & \multicolumn{1}{c|}{ Deskripsi } \\
\hline 1 & Ngaseuk & $\begin{array}{l}\text { Ritual awal menanam padi (berziarah, } \\
\text { makan nasi kebuli, dan menampilkan } \\
\text { hiburan kesenian) }\end{array}$ \\
\hline 2 & Sapangjadian pare & Ritual memohon ijin pada leluhur \\
\hline 3 & Sawenan & Ritual upacara setelah padi keluar \\
\hline 4 & Beberes mager & Ritual menjaga padi dari serangan hama \\
\hline 5 & Ngarawunan & Ritual meminta isi padi dari serangan hama \\
\hline 6 & Mipit & Ritual panen (dimulai Abah memetik padi) \\
\hline 7 & Nutu & Ritual menumbuk padi \\
\hline 8 & Ronggokan & Ritual menyerahkan biaya seren taun \\
\hline 9 & Nganyaran & Ritual saat padi ditumbuk dan dimasak \\
\hline 10 & Tutup nyambut & $\begin{array}{l}\text { Ritual acara selametan yang menandakan } \\
\text { selesainya semua aktivitas pertanian }\end{array}$ \\
\hline 11 & Turun nyambut & $\begin{array}{l}\text { Ritual membuka kegiatan pertanian setelah } \\
\text { upacara seren taun }\end{array}$ \\
\hline 12 & Seren taun & $\begin{array}{l}\text { Ritual puncak tradisi dari seluruh } \\
\text { rangkaian kegiatan pertanian }\end{array}$ \\
\hline 13 & Beberes bengkong & Ritual saat kegiatan mengkhitan \\
\hline
\end{tabular}

\section{PENUTUP}

Klasifikasi leksikon bahasa Sunda yang ditemukan di Kasepuhan Ciptagelar, Kasepuhan Ciptamulya, dan Kasepuhan Sinarresmi Kecamatan Cisolok, Kabupaten Sukabumi berupa kata dan frasa (nominal dan verbal) yang dikategorikan dalam tiga kategori yaitu Politik (Sistem Kepengurusan Adat), Sistem Kepercayaan, Ritual (Upacara Menghargai Leluhur). Leksikon-leksikon yang ditemukan dalam kategori Politik (Sistem Kepengurusan Adat) terdapat 14 leksikon yaitu sesepuh girang, baris kolot, gandek, ema beurang, tukang bebersih (kemit), penghulu, bengkong, 
paraji, tukang moro, dukun, ngurus leuit, canoli, tukang dapur, tukang panday. Selanjutnya, leksikon-leksikon bahasa Sunda yang ditemukan dalam kategori Sistem Kepercayaan terdapat 15 leksikon yaitu mupusti pare lain migusti, saiketan sabeungkutan, ngajaga leuweng, incu putu, leuweung kolot, leuweung titipan, leuweung sempalan, upacara (ngaseuk, mipit, nganyaran), tatali paranti karuhun, tetekon, tilu sapamilu, dua sakarupa, hiji eta keneh, nyanghulu ka hukum, nunjang ka nagara, mufakat jeung balea, ucap lampah kalawan tekad, wedal, leuit. Terakhir adalah temuan leksikon bahasa Sunda yang dikategorikan Ritual (Upacara Menghargai Leluhur) data ditemukan sebanyak 13, antara lain ngaseuk, sapangjadian pare, sawenan, beberes mager, ngarawunan, mipit, nutu, ronggokan, nganyaran, tutup nyambut, turun nyambut, seren taun, dan beberes bengkong. Total data yang ditemukan mengenai konsep hidup dalam leksikon bahasa Sunda masyarakat adat Kasepuhan Banten Kidul Kecamatan Cisolok Kabupaten Sukabumi yang terdapat di Kasepuhan Ciptagelar, Kasepuhan Ciptamulya, dan Kasepuhan Sinarresmi sebanyak 42 data.

Untuk melengkapi penelitian ini masih banyak research gap dan temuan novelty yang harus mendukung temuan-temuan leksikon bahasa Sunda yang ada di konsep hidup Kasepuhan Ciptagelar, Kasepuhan Ciptamulya, dan Kasepuhan Sinarresmi. Seperti kajian linguistik historis komparatif untuk melihat variasi kekerabatan bahasa Sunda secara diakronis kualitatif dan dialektologi untuk memperjelas perbedaan-perbedaan unsur linguistik secara sinkronis kualitatif.

\section{DAFTAR PUSTAKA}

Fernandez, I.Y. (2008). “Kategori dan ekspresi linguistik dalam bahasa Jawa sebagai cermin kearifan lokal penuturnya: kajian etnolinguistik pada masyarakat petani dan nelayan". Kajian Linguistik dan Sastra, Vol. 20 No 2.
Koentjaraningrat. (1981). Beberapa pokok antropologi sosial. Jakarta: Dian Rakyat.

Maulidiah, R. (2019). “Istilah-istilah kearifan lokal masyarakat Melayu Asahan: kajian etnolinguistik". Jurnal Komunitas Bahasa, 7 (1), 39-46.

Nurnaningsih. (2019). “Kearifan lokal bahasa jawa dalam tradisi tingkeban di Kelurahan Laweyan Kotamadya Surakarta (sebuah kajian etnolinguistik)". Journal of Language Education, Literature, and Local Culture, 1 (1), 81-95.

Palmer, G.B. (1996). Toward a theory of cultural linguistics. Usa: The University of Texas Press.

Rais, W.A. (2012). Kearifan lokal cara memanfaatkan lingkungan alam yang tercermin dalam ekspresi verbal dan non verbal nelayan di Pesisir Selatan Kebumen: Kajian etnolinguistik. Medan Bahasa, 6(2), 223.

Rais, W.A. (2012). “Kearifan lokal dalam bahasa dan budaya Jawa orang Samin di Kabupaten Blora: Kajian etnolinguistik". Medan Bahasa, 6(2), 207.

Riana, I.K. (2003). "Linguistik Budaya: Kedudukan dan Ranah Pengkajiannya". dalam pidato pengukuhan guru besar tetap dalam bidang linguistikbudaya pada Fakultas Sastra Unud. Denpasar: Universitas Udayana.

Santoso, R. (2012). Metodologi penelitiaan kebahasaan. UNS Press.

Sugianto, Alip. (2015). “Kajian etnolinguistik terhadap pakaian adat Warok Ponorogo". Jurnal Aristo Vol 3 No 1.

Tondo, F.H. (2013). “Bahasa minoritas hamap dalam perkebunan jagung: tinjauan etnolinguistik". Jurnal Pendidikan dan Kebudayaan, Vol. 18. 2.

Wua, H. \& Marwati. (2019). “Leksikon penunjuk waktu dalam bahasa muna (kajian etnolinguistik)". Jurnal Pendidikan Bahasa, 1 (8), 22-31. 